\title{
Oncogenic KRAS sensitises colorectal tumour cells to chemotherapy by p53-dependent induction of Noxa
}

\author{
MT de Bruijn', DAE Raats', FJH Hoogwater', WJ van Houdt', K Cameron², JP Medema ${ }^{2}$, IHM Borel Rinkes' and \\ O Kranenburg*,I
}

'Department of Surgery, University Medical Center Utrecht, Heidelberglaan 100, 3584CX Utrecht, The Netherlands; '2Laboratory of Experimental Oncology and Radiobiology, Center for Experimental Molecular Medicine, Academic Medical Center, Meibergdreef 9, I I05 AZ Amsterdam,

The Netherlands

\begin{abstract}
BACKGROUND: Oxaliplatin and 5-fluorouracil (5-FU) currently form the backbone of conservative treatment in patients with metastatic colorectal cancer. Tumour responses to these agents are highly variable, but the underlying mechanisms are poorly understood. Our previous results have indicated that oncogenic KRAS in colorectal tumour cells sensitises these cells to chemotherapy.

METHODS: FACS analysis was used to determine cell-cycle distribution and the percentage of apoptotic and mitotic cells. A multiplexed RT-PCR assay was used to identify KRAS-controlled apoptosis regulators after exposure to 5-FU or oxaliplatin. Lentiviral expression of short-hairpin RNAs was used to suppress p53 or Noxa.

RESULTS: Oncogenic KRAS sensitised colorectal tumour cells to oxaliplatin and 5-FU in a p53-dependent manner and promoted p53 phosphorylation at Ser37 and Ser392, without affecting p53 stabilisation, p2 I induction, or cell-cycle arrest. Chemotherapy-induced expression of the p53 target gene Noxa was selectively enhanced by oncogenic KRAS. Suppression of Noxa did not affect p2 I induction or cell-cycle arrest, but reduced KRAS/p53-dependent apoptosis after exposure to chemotherapy in vitro and in tumour xenografts. Noxa suppression did not affect tumour growth per se, but strongly reduced the response of these tumours to chemotherapy.

CONCLUSION: Oncogenic KRAS determines the cellular response to p53 activation by oxaliplatin or 5-FU, by facilitating apoptosis induction through Noxa.
\end{abstract}

British Journal of Cancer (2010) 1 02, 1254- 1264. doi:I0.1038/sj.bjc.6605633 www.bjcancer.com

Published online 30 March 2010

(c) 2010 Cancer Research UK

Keywords: KRAS; p53; Noxa; oxaliplatin; 5-fluorouracil; colorectal

Chemotherapy of colorectal cancer mainly involves the fluoropyrimidine drug 5-fluorouracil (5-FU) and the platinum drug oxaliplatin (Chau and Cunningham, 2009). The response of colorectal tumours to these compounds is determined both by the genetic background of tumour cells as well as by environmental cues. Colorectal tumours frequently harbour activating mutations in the KRAS proto-oncogene, which drives tumour progression (Andreyev et al, 1998, 2001). Signalling by constitutively active Ras proteins can either promote or prevent the induction of apoptosis, depending on the cellular context and on the specific isoform studied (Vos et al, 2000; Khokhlatchev et al, 2002). For instance, the expression of oncogenic N-Ras but not that of oncogenic K-Ras in the colonic epithelium provides protection against enterocyte apoptosis in a colitis model (Haigis et al, 2008). In contrast, we along with others have previously shown that oncogenic KRAS promotes apoptosis of human colorectal tumour cells exposed to either 5-FU or oxaliplatin (Klampfer et al, 2005; Smakman et al, 2006). Although activating mutations in KRAS alone do not reliably predict the response of

*Correspondence: Dr O Kranenburg;

E-mail: o.kranenburg@umcutrecht.nl

Received 6 November 2009; revised 25 February 2010; accepted 4 March 2010; published online 30 March 2010 colorectal tumours to chemotherapy (Loriot et al, 2009), these findings do suggest that the acquisition of KRAS mutations may be associated with an increased propensity to undergo apoptosis. Interestingly, several studies have connected Ras signalling to the activation of p53 (Ries et al, 2000; Lin and Lowe, 2001; Ferbeyre et al, 2002). In non-transformed cells, the activation of p53 by oncogenic Ras induces a permanent cell-cycle exit and induction of cellular senescence (Serrano et al, 1997; Bardeesy and Sharpless, 2006; Ruiz et al, 2008). However, p53 activation in (colorectal) tumour cells does not lead to senescence, but rather leads to apoptosis or cell-cycle arrest (Aneja et al, 2007; Toscano et al, 2007; Braun et al, 2008). The tumour suppressor protein p53 is a key player in determining the response of colorectal tumour cells to oncogenic stress and chemotherapy by oxaliplatin and 5-FU (Vousden and Lu, 2002; Adamsen et al, 2007; Borralho et al, 2007; Toscano et al, 2007). The determinants specifying p53 signalling output are the subject of intense investigation. Although p53-induced activation of the CDK inhibitor p21 is sufficient to cause cell-cycle arrest in most cell types, p53-induced apoptosis is more complex and involves the activation of different sets of target genes in different tissues and in response to different stimuli (Oren, 2003; Yu and Zhang, 2005; Kuribayashi and El-Deiry, 2008; Vousden and Prives, 2009). In colorectal tumour cells, the p53upregulated modulator of apoptosis (PUMA) has an important role in the induction of apoptosis exposed to 5-FU or oxaliplatin (Wang et al, 
2007). The p53-upregulated modulator of apoptosis belongs to the family of 'BH3-only' proteins that promote apoptosis by neutralising Bcl-2 family pro-survival proteins, including $\mathrm{Bcl}-2, \mathrm{Bcl}-\mathrm{x}_{\mathrm{L}}$, and myeloid cell leukaemia sequence 1 (Mcl-1) (Willis and Adams, 2005; Shibue and Taniguchi, 2006). p53 also promotes the expression of Noxa, another BH3-only family member (Oda et al, 2000). The p53-upregulated modulator of apoptosis is generally considered to be a more potent apoptosis inducer than Noxa, because it can neutralise multiple Bcl-2 family members, whereas Noxa selectively neutralises Mcl-1 (Willis and Adams, 2005; Shibue and Taniguchi, 2006; Ploner et al, 2008). However, Noxa-dependent cell death may be particularly important in malignant cells (Suzuki et al, 2009), and Noxa could therefore represent a potential therapeutic target.

In this report, we studied the contribution of p53 and p53 target genes to KRAS-induced sensitisation of colorectal tumour cells to 5-FU and oxaliplatin. We found that the mutant KRAS cooperates with p53 in the induction of Noxa, but not other pro-apoptotic p53 target genes. Furthermore, we show that Noxa does not control tumour growth per se, but is an important determinant of the tumour response to chemotherapy.

\section{MATERIALS AND METHODS}

\section{Cell culture}

The human colorectal cancer cell line HCT116 $6^{\mathrm{G} 13 \mathrm{D} / \mathrm{wt}}$ and the isogenic cell line $\mathrm{Hkh} 2^{\mathrm{ko} / \mathrm{wt}}$ lacking the KRAS ${ }^{\mathrm{D} 13}$ allele were kindly provided by Shirasawa et al (1993). HCT116 p53KO cells were kindly provided by Dr Vogelstein. All cells were cultured in Dulbecco's modified Eagle's medium (Dulbecco, ICN Pharmaceuticals, Costa Mesa, CA, USA) supplemented with $5 \%(\mathrm{v} / \mathrm{v})$ fetal calf serum, $2 \mathrm{~mm}$ glutamine, $0.1 \mathrm{mg} \mathrm{ml}^{-1}$ streptomycin, and $100 \mathrm{U} \mathrm{ml}^{-1}$ penicillin. All cells were kept at $37^{\circ} \mathrm{C}$ in a humidified atmosphere containing $5 \% \quad \mathrm{CO}_{2}$. Oxaliplatin was obtained from Sanofi Aventis (Gouda, The Netherlands) and 5-FU was from TEVA (Haarlett, The Netherlands).

\section{Antibodies}

The following antibodies were obtained from Cell Signaling Technology Inc. (Danvers, MA, USA): anti-Puma (no. 4976), anti-caspase-8 1C12 (no. 9746), anti-cleaved caspase-3 ASP175 (no. 9661), and the secondary antibody peroxidase-conjugated antirabbit IgG. The following antibodies were all obtained from Santa Cruz Biotechnology (Heidelberg, Germany): anti-p53 DO-1 (sc-126) and anti-p21 C19 (sc-397). Anti-Noxa (IMG-349A) was purchased from Imgenex Corporation (San Diego, CA, USA); anti- $\alpha$ tubulin from Sigma Aldrich (St Louis, MO, USA); anti- $\beta$-actin AC-15 (NB600-501) from Novus Biologicals LLC (Littleton, CA, USA); secondary antibody peroxidase-conjugated anti-mouse IgG from Dako (Glostrup, Denmark); anti-phospho-histone H3 (Ser10) (06-570) from Millipore (Billerica, MA, USA); and the secondary antibody Cy5 AffiniPure $\mathrm{F}\left(\mathrm{ab}^{\prime}\right)_{2}$ Frag Donkey anti-rabbit IgG from Jackson Immunoresearch Europe (Suffolk, UK). For immunohistochemical staining, anti-Ki-67 clone SP-6 (no. RM-9106S) was acquired from Lab Vision Products Thermo Fisher Scientific (Chesire, UK) and anti-cleaved caspase-3 (no. 559565) from BD Pharmingen (Franklin Lakes, NJ, USA) was used.

\section{Lentiviral constructs and transduction}

The lentiviral short-hairpin RNA (shRNA) construct targeting p53 was kindly provided by $\mathrm{Dr}$ AG Jochemsen. Noxa-targeting lentiviral constructs were obtained from the TRC-Mm1.0 library (Sigma Aldrich). The target set used for Noxa (NM_021127) included TRCN0000150555, TRCN0000155978, TRCN0000151311, TRCN0000153637, and TRCN0000155570. Of these constructs, subsequent transduction of cells with TRCN0000151311, followed by transduction with TRCN0000153637 produced the best knock down. As the control vector, we used the same vector containing a sequence targeting luciferase, TGACCAGGCATTCACAGAAAT. For virus production, we used the third-generation packaging system, kindly provided by Professor D Trono.

\section{p53 phosphorylation status}

The phosphorylation status of p53 was analysed using the phosphop53 antibody sampler kit no. 9919 (Cell Signaling Technology Inc.).

\section{FACS analysis}

Cells were fixed in $70 \%$ ice-cold ethanol and incubated for $2 \mathrm{~h}$ at $4{ }^{\circ} \mathrm{C}$. To determine the percentage of mitosis, cells were washed in PBSTween $(0.1 \%)$ and incubated with anti-phospho-histone H3 antibody for $1 \mathrm{~h}$ at RT, after which cells were incubated with CY5-labelled secondary antibody for $1 \mathrm{~h}$ at RT. To assess the cell-cycle profile, fixed cells were treated with RNAse and DNA was stained with propidium iodide (PI). All samples were analysed by bivariate flow cytometry using Cell Quest and Modfit software (Becton Dickinson, Breda, The Netherlands).

\section{MLPA}

The MLPA was performed according to the manufacturer's protocol (MRC-Holland BV, Amsterdam, The Netherlands).

\section{RT - PCR}

The RT - PCR was performed by isolating RNA using Trizol, and conversion to cDNA using Superscript2 (Invitrogen, Breda, The Netherlands). The primers used were for Noxa forward: $5^{\prime}-\mathrm{G}$ GTACCCTGGGAAGAAGGCGCG- $3^{\prime}$ and reverse: $5^{\prime}$-GAATTCT CAGGTTCCTGCGCAGAAG-3'. L32 served as a loading control with the forward primer: $5^{\prime}$-GCCCAAGATCGTCAAAAAGA- $3^{\prime}$, and reverse 5'-ATTGTGGACCAGGAACTTGC-3'.

\section{Immunofluorescence}

Immunofluoresence was performed as described in the study by Lindqvist et al (2007). Images were acquired on a Zeiss LSM510 META microscope (Zeiss, Sliedrecht, The Netherlands). MitoTracker (Invitrogen) was used according to the manufacturer's protocol.

\section{Tumour model and chemotherapy}

All experiments were conducted in accordance with the guidelines of the Animal Welfare Committee of the University Medical Center Utrecht, The Netherlands. Male Balb/C Nu/Nu mice (10 - 12 weeks) were purchased from Charles River (Sulzfeld, Germany) and were housed in filter top cages. Tumour cells were injected subcutaneously $\left(10^{6}\right.$ cells in $100 \mu \mathrm{l} 1 / 3$ diluted Matrigel (Becton Dickinson)). When tumours reached $\sim 100 \mathrm{~mm}^{3}$, mice were treated with $12.5 \mathrm{mg} \mathrm{kg}^{-1}$ oxaliplatin or vehicle intraperitoneally (day 0 ). A second dose of oxaliplatin $\left(12.5 \mathrm{mg} \mathrm{kg}^{-1}\right)$ was administered on day 7. Tumour growth was assessed every 2 days, and mice were terminated 14 days after the start of treatment. The volume $(V)$ was calculated by $V=A \times B^{2} \times 0.5236$ ( $A=$ largest diameter, $B=$ diameter perpendicular to $A$ ).

\section{RESULTS}

KRAS $^{\text {D13 }}$ sensitises tumour cells to chemotherapy-induced apoptosis without overriding cell-cycle arrest

Oncogenic KRAS may sensitise tumour cells to apoptosis induction by forcing cell-cycle progression in the presence of 
DNA damage. Therefore, we analysed whether KRAS-facilitated apoptosis induction by 5-FU and oxaliplatin was accompanied by escape from cell-cycle arrest. HCT116 (KRAS $\left.{ }^{\mathrm{wt} / \mathrm{D} 13}\right)$ and isogenic Hkh2 cells $\left(\mathrm{KRAS}^{\mathrm{wt} / \mathrm{ko}}\right)$ were treated with oxaliplatin and 5-FU for three consecutive days. Apoptosis induction and cell-cycle distribution were then measured by FACS analysis of PI-stained cells. In addition, mitotic progression was measured by FACS analysis of phospho-histone H3-positive cells.
We found that KRAS greatly facilitated apoptosis induction by both chemotherapeutics as described previously (Klampfer et al, 2005; Smakman et al, 2006) (Figure 1A and B). HCT116 cells underwent a bona fide cell-cycle arrest and did not enter mitosis before apoptosis induction (Figure 1C). This suggests that KRAS does not promote chemotherapyinduced apoptosis by forcing mitotic entry in the presence of DNA damage.
A

Oxaliplatin

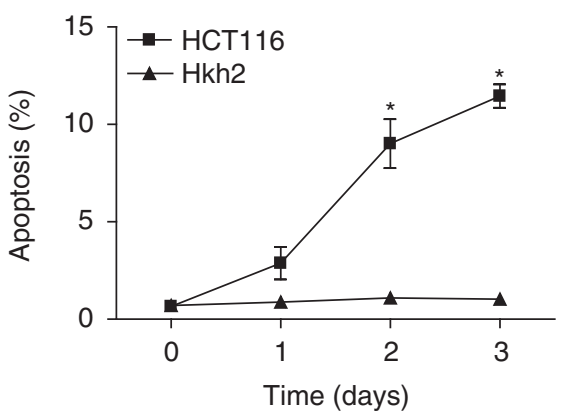

B
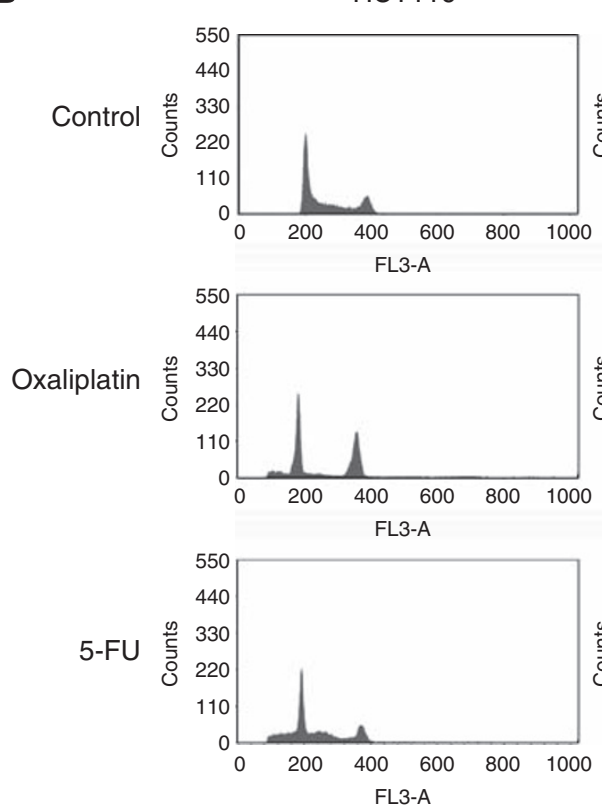

C

Oxaliplatin

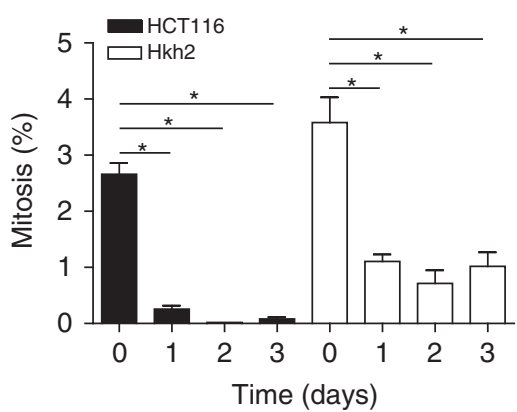

5-FU

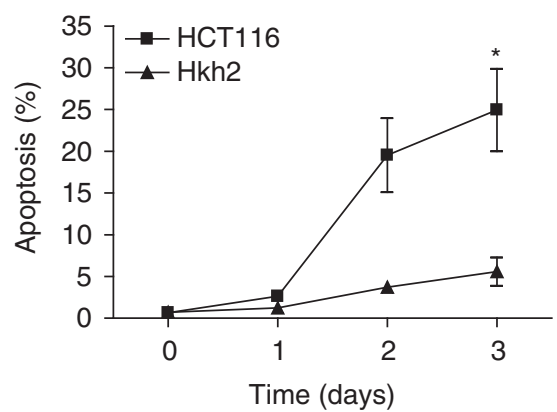

Hkh2
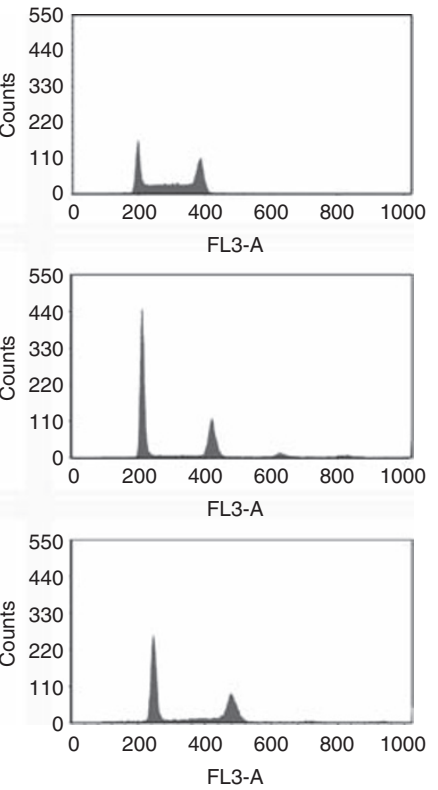

$5-\mathrm{FU}$

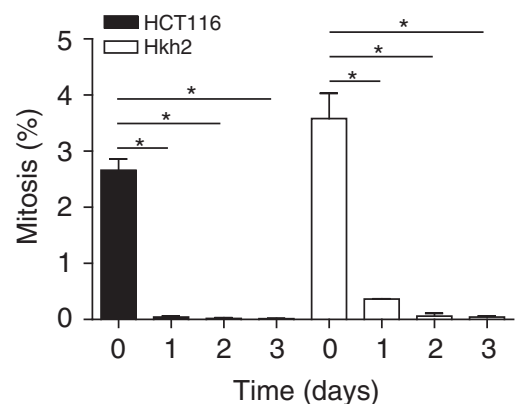

Figure I KRAS DI3 sensitises tumour cells to chemotherapy-induced apoptosis without overriding cell-cycle arrest. (A) HCTII6 and Hkh2 cells were treated with $8 \mu \mathrm{g} \mathrm{ml}^{-1}$ oxaliplatin or $8 \mu \mathrm{g} \mathrm{ml} l^{-1}$ 5-FU for three consecutive days. Cells were then fixed in formalin and stained with propidium iodide (PI). The sub-GI fraction was determined by FACS analysis. Error bars represent s.e.m. based on three independent experiments $(* P<0.05)$. (B) Cells were treated as described in panel A. After 2 days, cells were fixed and the cycle profiles of Pl-stained cells were analysed by FACS. (C) Cells were treated as described in panel $\mathrm{A}$ and fixed at the indicated time points. Mitotic cells were then stained using anti-phospho-histone H3 and analysed by FACS. Error bars represent s.e.m., based on three independent experiments $(* P<0.00 \mathrm{I})$. 
KRAS $^{\mathrm{D} 13}$ promotes apoptosis without affecting p53 stabilisation or p21 induction

Next, we tested whether the KRAS status would influence p53 stabilisation. We found that p53 was stabilised to a similar extent in both HCT116 and Hkh2 cells in response to either oxaliplatin or 5-FU (Figure 2A). Nuclear accumulation of p53 was also similar in both cell types (Figure 2B). We were unable to detect p53 localisation to the mitochondria in oxaliplatin- or 5-FU-treated HCT116 or Hkh2 cells (Supplementary Figure 1). However,

$$
\text { A }
$$$$
\text { Oxaliplatin }
$$$$
5-\mathrm{FU}
$$

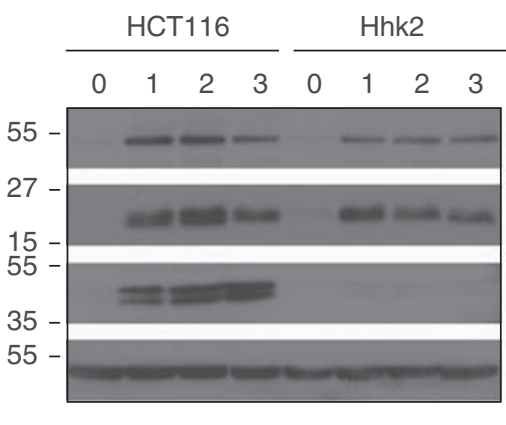

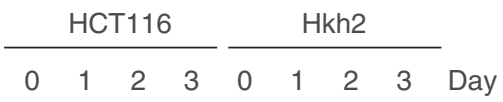

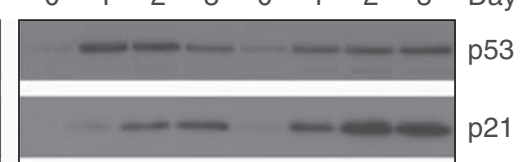

B

HCT116

Hkh2
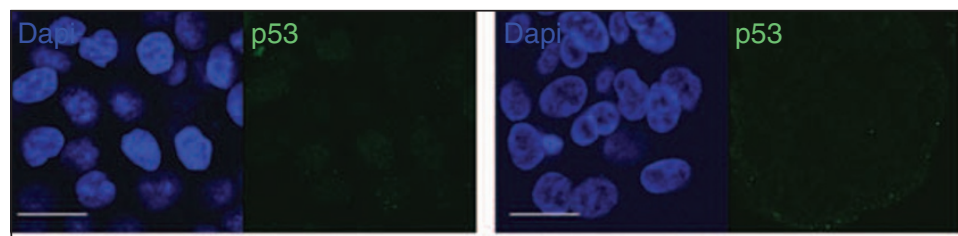

Control
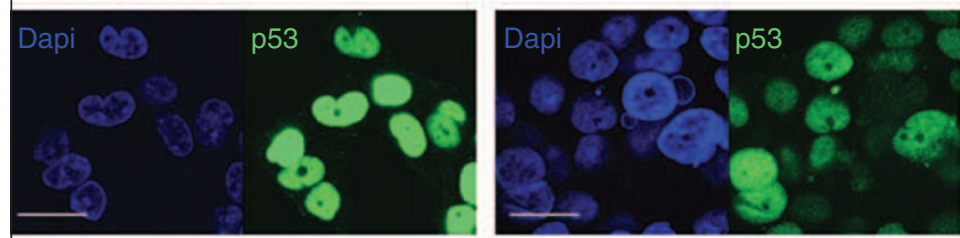

Caspase-8 (cleaved) p43/p41

$\alpha$-Tubulin
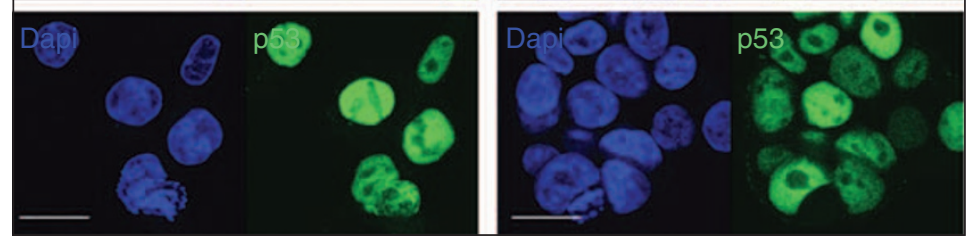

Oxaliplatin

C

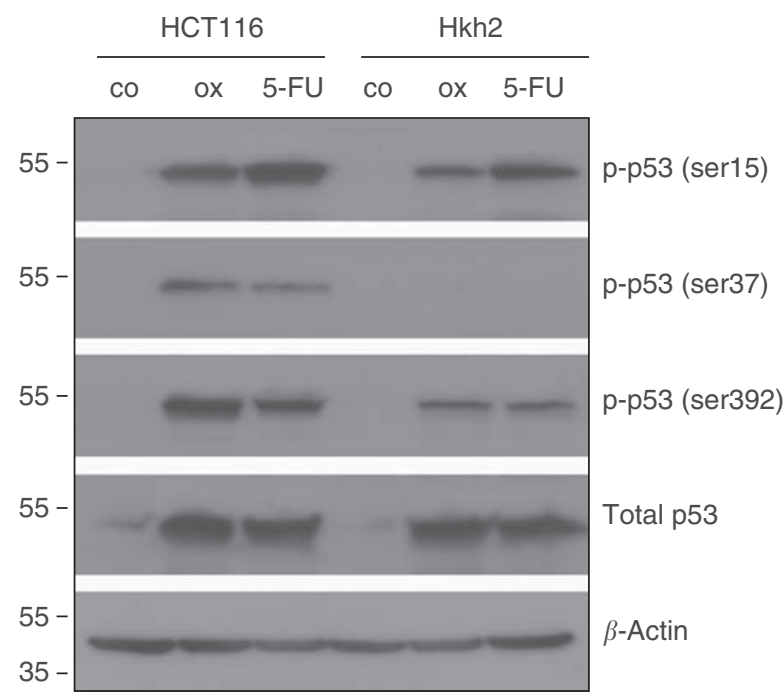

Figure 2 Oncogenic KRAS promotes apoptosis without affecting p53 stabilisation or p2I induction. (A) HCTII6 and Hkh2 cells were treated with oxaliplatin $\left(8 \mu \mathrm{g} \mathrm{ml}^{-1}\right)$ or 5 -FU $\left(8 \mu \mathrm{g} \mathrm{ml}^{-1}\right)$ for $0-3$ days as indicated. Lysates were prepared and analysed for the presence of p53, p2 I, cleaved caspase-8, tubulin, and actin by western blotting. (B) HCTI 16 and Hkh2 cells were treated for $24 \mathrm{~h}$ with oxaliplatin or 5-FU. Cells were then processed for immunofluorescence analysis of p53 localisation. Bars represent $50 \mu \mathrm{m}$. (C) Cells were treated as described in panel B and cell lysates were analysed for the presence of p53 (total p53) and p53 phosphorylated at residues Ser6, Ser9, Ser15, Ser20, Ser37, Ser46, and Ser392. The signals for Ser6, Ser9, Ser20, and Ser46 were below the detection limit. 
whereas p53 stabilisation correlated caspase- 8 cleavage in HCT116 cells, this was not observed in Hkh2 cells (Figure 2A). Induction of the cyclin-dependent kinase inhibitor and p53 target p21 by chemotherapy was not affected by KRAS status (Figure 2A), which is in line with the finding that both apoptosis-prone and apoptosisresistant cells undergo cell-cycle arrest.

\section{KRAS promotes p53 phosphorylation of p53 on Ser37 and Ser392}

The differential regulation of p53 target genes is controlled by both post-translational modification and its binding partners. In this study, we tested whether KRAS status modified chemotherapy-induced phosphorylation of $\mathrm{p} 53$. We found that oxaliplatin- or 5-FU-induced p53 phosphorylation on Ser15 was not altered, but phosphorylation on Ser37 and Ser392 was far more pronounced in cells expressing oncogenic KRAS (Figure 2C). Again, p53 stabilisation was not different between HCT116 and Hkh2 cells (Figure 2C).

\section{p53 is required for $\mathrm{KRAS}^{\mathrm{D13}}$-stimulated tumour cell sensitisation to apoptosis}

Next, we tested whether p53 was required for the sensitising effect of KRAS ${ }^{\mathrm{D} 13}$ on chemotherapy-induced tumour cell apoptosis. To this end, we created stable p53 knockdown cell lines by using
A

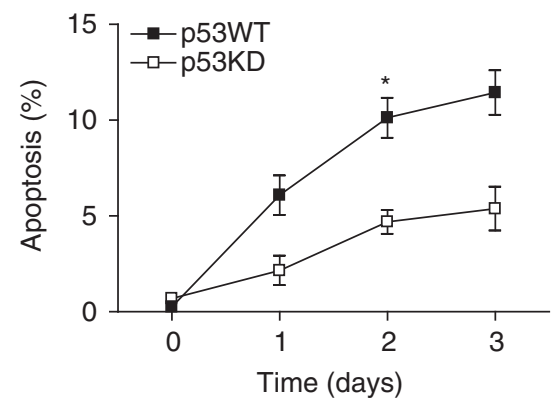

Hkh2 oxaliplatin

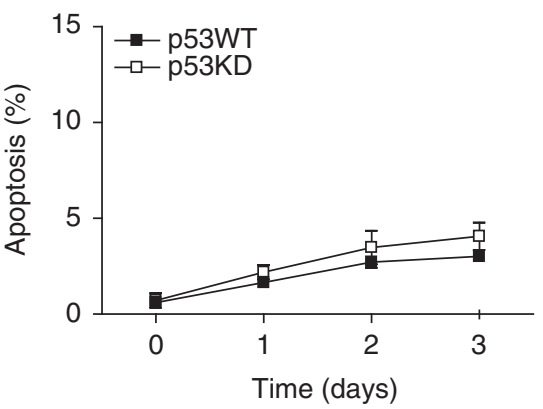

B
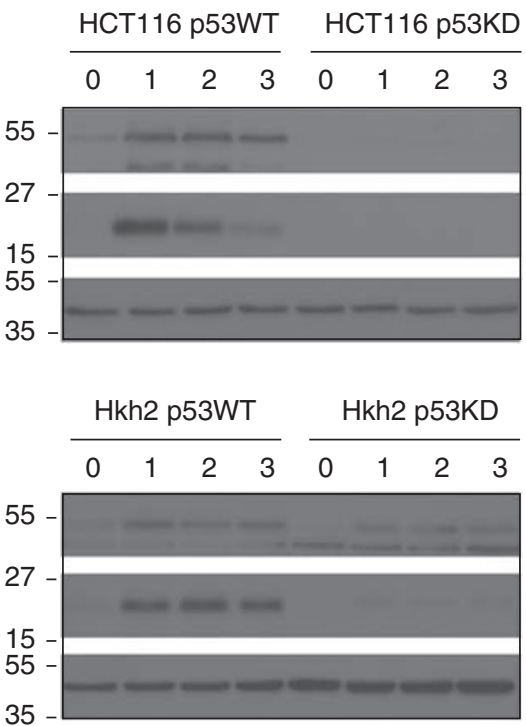

HCT116 5-FU

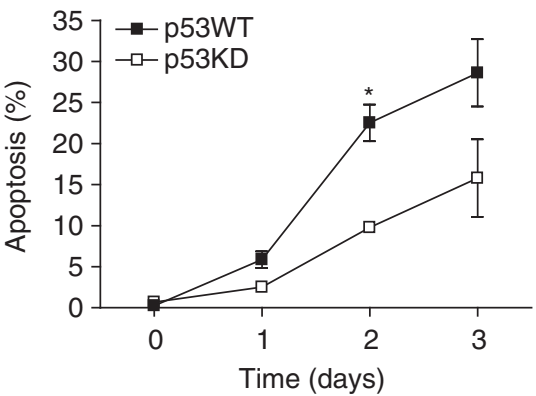

Hkh2 5-FU

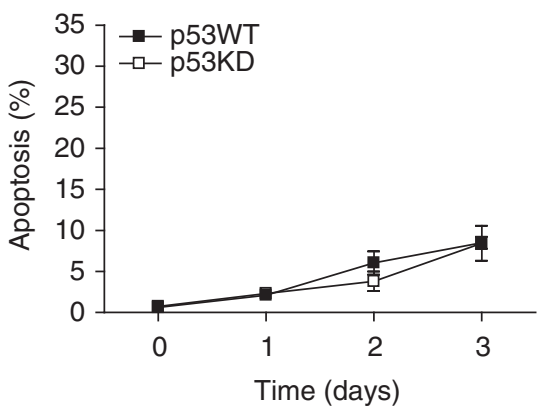

$5-\mathrm{FU}$
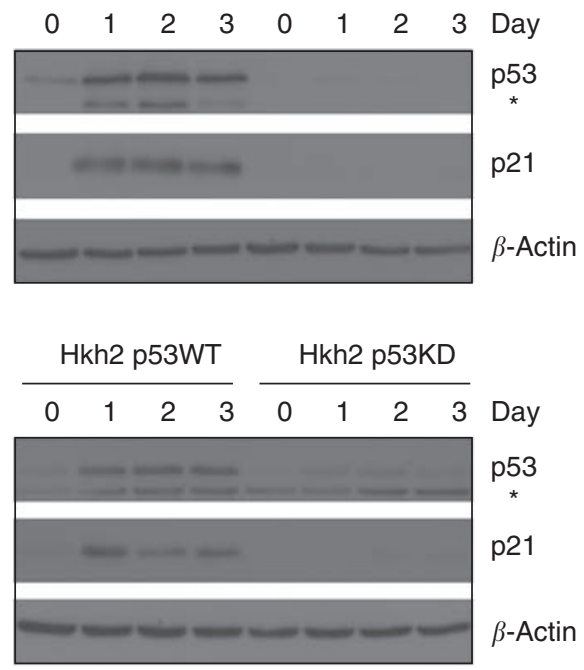

Figure 3 Wild-type p53 is required for sensitisation to apoptosis by oncogenic KRAS. (A) HCTII6 and Hkh2 cells were transduced with a lentiviral control shRNA vector, and with a vector targeting p53. All four cell lines were then treated for $0-3$ days with oxaliplatin $\left(8 \mu \mathrm{g} \mathrm{ml}^{-1}\right)$ or 5 -FU $\left(8 \mu \mathrm{g} \mathrm{ml}{ }^{-1}\right)$. After fixation, cells were stained with propidium iodide and the sub-GI fraction was determined by FACS analysis. Error bars represent s.e.m. of three independent experiments $\left({ }^{*} \mathrm{P}<0.05\right)$. (B) Cells were treated as described in panel A, and cell lysates were prepared and analysed for the presence of p53 and p2I by western blotting. 


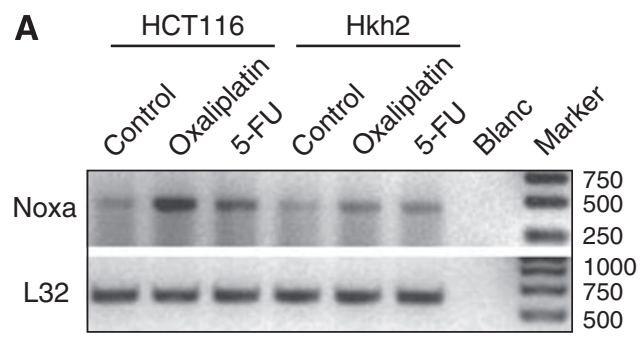

B
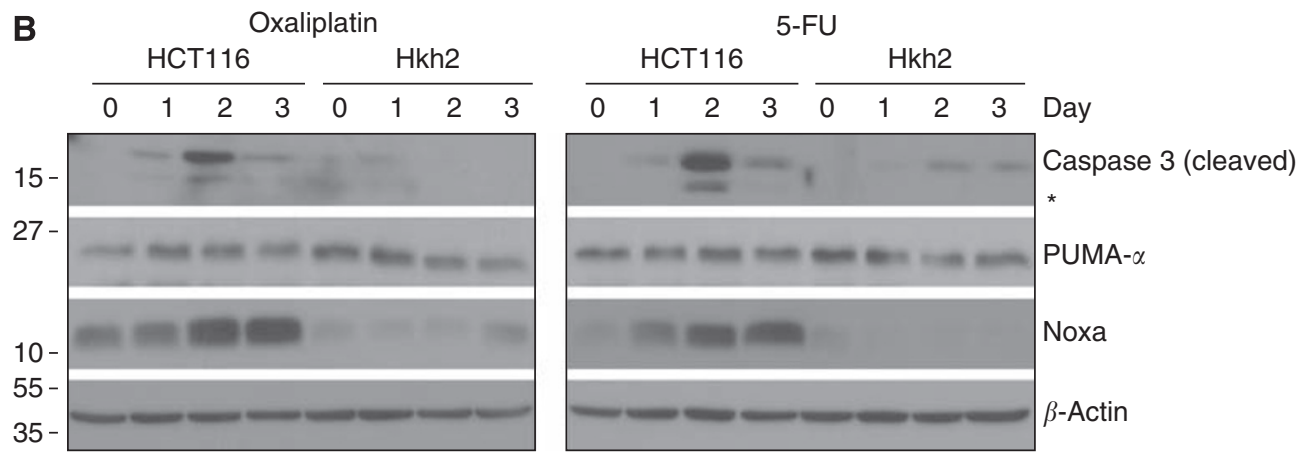

C

Oxaliplatin

5 -FU
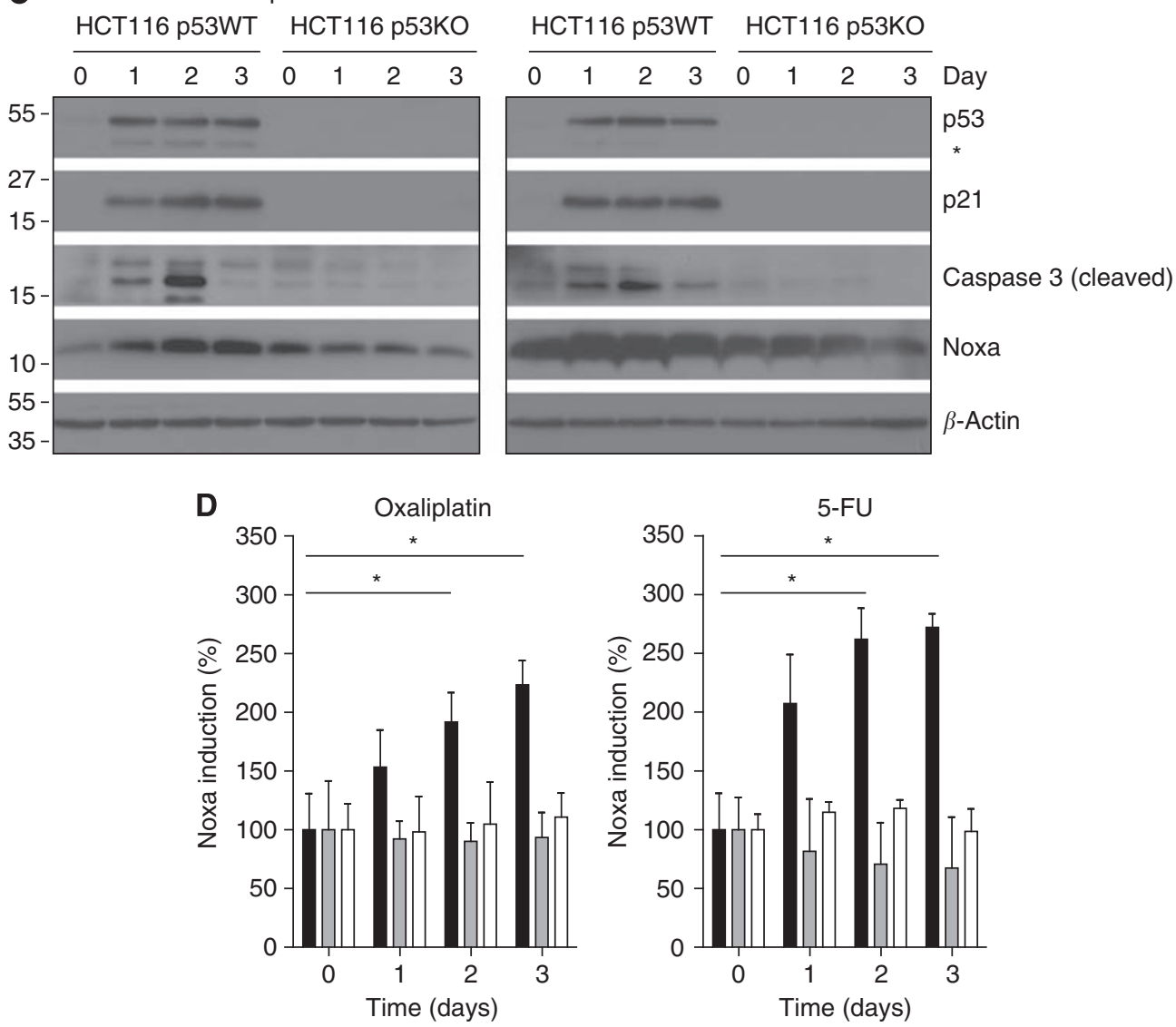

- HCT116 $\square$ Hkh2 $\square$ HCT116 p53KO

Figure 4 Oncogenic KRAS is required for p53-dependent induction of Noxa by chemotherapy. (A) HCTII6 and Hkh2 cells were treated with oxaliplatin $\left(8 \mu \mathrm{g} \mathrm{ml}^{-1}\right)$ or 5-FU $\left(8 \mu \mathrm{g} \mathrm{ml}^{-1}\right)$ for $24 \mathrm{~h}$. Total RNA was then isolated and tested for the presence of Noxa and L32 mRNA by RT-PCR. (B) Cells were treated for $0-3$ days with oxaliplatin or 5-FU, and Noxa protein levels were determined by western blot analysis. (C) HCTII6 expressing ( $\mathrm{HCT} 116$ p53WT) or lacking p53 ( $\mathrm{HCT} 116$ p53KO) were cultured in the presence of oxaliplatin or 5-FU for 0 - 3 days as indicated. Lysates were prepared and analysed for the presence of p53, p2I, PUMA, and Noxa protein levels. (D) The experiment described in panel C was repeated three times and all Noxa blots were scanned densitometrically to quantify the induction. Graphs represent \% induction relative to day 0 . *Indicates statistically significant differences $(P<0.05)$. 

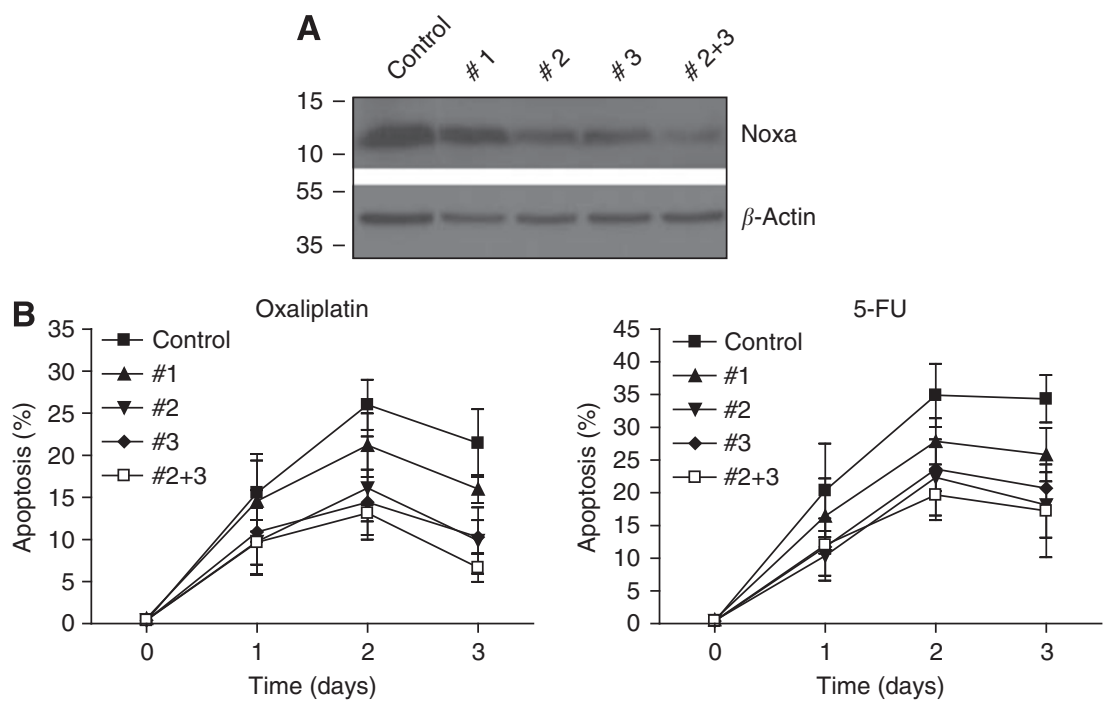

Figure 5 Contribution of Noxa to KRAS-facilitated apoptosis induction in response to chemotherapy. (A) HCTI I 6 cells were transduced with lentiviral vectors targeting Noxa (no. I, no. 2, no. 3, and no. 2 + no. 3), or with a vector targeting firefly luciferase (control). After selection in puromycin-containing medium for I week, cells were lysed and analysed for Noxa protein levels by western blot analysis. (B) HCTI I 6 control and Noxa knockdown (NoxaKD) cells were treated with oxaliplatin $\left(8 \mu \mathrm{g} \mathrm{ml}^{-1}\right)$ or 5 -FU $\left(8 \mu \mathrm{g} \mathrm{ml}^{-1}\right)$ for $0-3$ days. The percentage of apoptotic cells was then determined by FACS analysis as in Figure I. Error bars represent s.e.m. of three independent experiments.

lentiviral RNA interference. Knockdown of p53 in HCT116 cells strongly reduced apoptosis in response to oxaliplatin or 5-FU in HCT116 cells (Figure 3A, upper panel). However, p53 knockdown did not affect 5-FU- or oxaliplatin-induced apoptosis in Hkh2 cells (Figure 3A, lower panel). In both cell types, p21 induction was completely abrogated (Figure 3B). These results show that the apoptosis-promoting effect of KRAS ${ }^{\text {D13 }}$ depends on the presence of wild-type p53.

\section{5-FU and oxaliplatin induction of Noxa requires oncogenic KRAS and wild-type p53}

To gain further insight into the mechanism by which oncogenic KRAS facilitates apoptosis induction in response to chemotherapy, we performed a multiplexed RT-PCR analysis (MLPA) for the induction of apoptosis control genes by either 5-FU or oxaliplatin in HCT116 and Hkh2 cells (Supplementary Figure 2A). Of the 32 genes tested in this screen, only Noxa (PMAIP1) was selectively induced in HCT116 cells. The Noxa-related PUMA gene was induced to a similar extent in HCT116 and Hkh2 cells by 5 -FU or oxaliplatin. However, chemotherapy induction of PUMA mRNA levels was relatively low. The PUMA/Noxa binding partner Mcl-1 was not induced by either drug (Supplementary Figure 2B). Both RT-PCR and western blot analysis confirmed the selective induction of Noxa in HCT116 cells, but not in Hkh2 cells (Figure $4 \mathrm{~A}$ and $\mathrm{B}$ ) and the relatively poor induction of PUMA (Figure 4B). Thus, induction of the p53 target gene Noxa by 5-FU and oxaliplatin requires the presence of oncogenic KRAS. Next, we tested the dependency of Noxa induction on p53 in HCT116 cells. As expected, the induction of Noxa by oxaliplatin or 5-FU was strongly reduced in cells lacking p53 (Figure 4C). Quantification of
Noxa induction in response to chemotherapy by densitometric scanning of the blots of three independent experiments showed that Noxa induction requires the presence of both wild-type p53 and oncogenic KRAS (Figure 4D).

\section{A critical role for Noxa in apoptosis induction by oxaliplatin and 5-FU}

We next tested whether KRAS-dependent induction of Noxa was instrumental in sensitising HCT116 cells to oxaliplatin and 5-FU. To this end, we created stable cell lines in which Noxa was suppressed by RNA interference. Of a set of five Noxa-targeting shRNA constructs, two (nos 2 and 3 ) reduced Noxa protein levels to $\sim 30 \%$ of control levels. Combination of these targeting constructs further reduced Noxa levels to $\sim 10 \%$ of control levels (Figure 5A). Exposure of control cells and Noxa-suppressed cells to either oxaliplatin or 5-FU showed that Noxa suppression protected HCT116 cells from apoptosis induction by $50-70 \%$ over a period of 3 days. In contrast, the relatively inefficient targeting construct no. 1 (20-30\% knockdown) had only a marginal protective effect (Figure 5A and $\mathrm{B}$ ), when compared with control cells expressing luciferase-targeting shRNA.

\section{Therapeutic efficacy of oxaliplatin and induction of tumour cell apoptosis requires Noxa}

We next tested whether suppression of Noxa affected tumour growth and therapy resistance. To this end, control HCT116 cells (luc-shRNA) and Noxa-suppressed HCT116 cells were injected into the flanks of nude mice and tumour growth was followed over time. When tumours reached a size of $100 \mathrm{~mm}^{3}$, PBS or oxaliplatin

Figure 6 Contribution of Noxa to the therapeutic efficacy of oxaliplatin and 5-FU. (A) Immune-deficient nude mice $(n=8$ per group) were injected subcutaneously with $10^{6} \mathrm{HCTI} 16$ control or HCTI I6-NoxaKD cells. When tumours reached a size of $100 \mathrm{~mm}^{3}$, the mice received either PBS or oxaliplatin $\left(12.5 \mathrm{mg} \mathrm{kg}^{-1}\right)$ intraperitoneally (day 0). Seven days later, all mice received a second dose of either PBS or oxaliplatin. Tumour growth was followed by caliper measurements every 2 days ( $* P=0.048, * * P=0.008$ ). (B) Tumours were harvested on day 7 and day I 4. Of each group, two tumours (panels $A$, B) were analysed for the presence of cleaved caspase-3 (as a marker for apoptosis) and for Noxa by western blotting. All tumours were analysed by immunohistochemistry for Ki-67 (C) and cleaved caspase-3 (D) as markers for proliferation and apoptosis respectively. Ten random fields per tumour were scored and the positive tumour areas were determined by automated computer analysis. The bar graphs represent the ratios of Ki-67 and caspase-3-positive surface areas in oxaliplatin-treated xenografts vs control xenografts $(* P<0.05)$. Representative images are shown on the right. Bars represent $50 \mu \mathrm{m}$ 
treatment was initiated. Tumour growth in control mice was unaffected by Noxa suppression (Figure 6A). Oxaliplatin treatment strongly reduced the growth of control HCT116 tumours, but had virtually no effect on Noxa-suppressed tumours (Figure 6A). Tumours were then excised and analysed by western blotting and immunohistochemistry, using $\mathrm{Ki}-67$ and activated caspase- 3 as
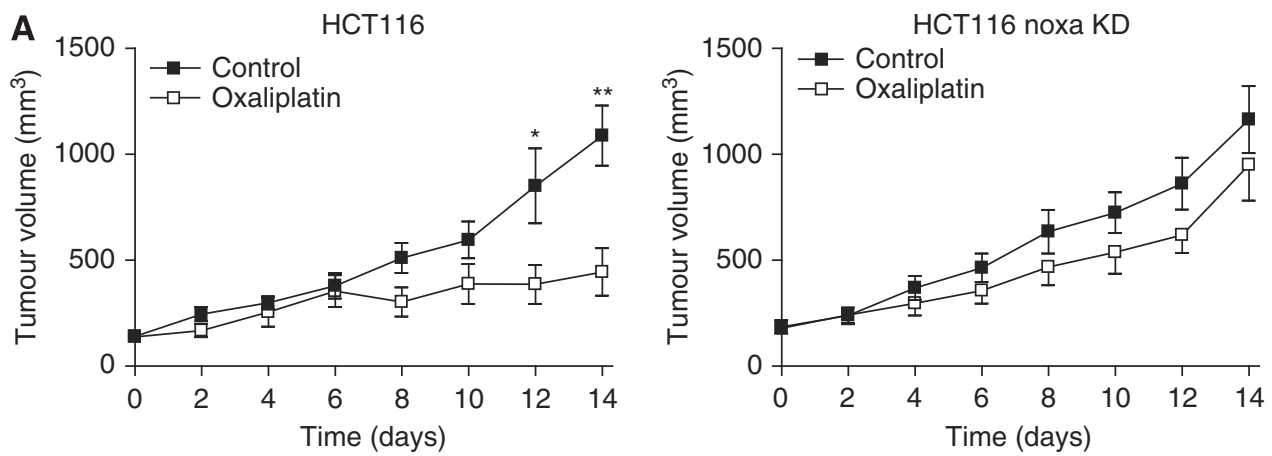

B $\frac{\text { HCT116 }}{\frac{\text { Control }}{\text { A B }} \frac{\text { ox }}{\text { A B B }}} \frac{}{\text { HCT116 noxa KD }}$
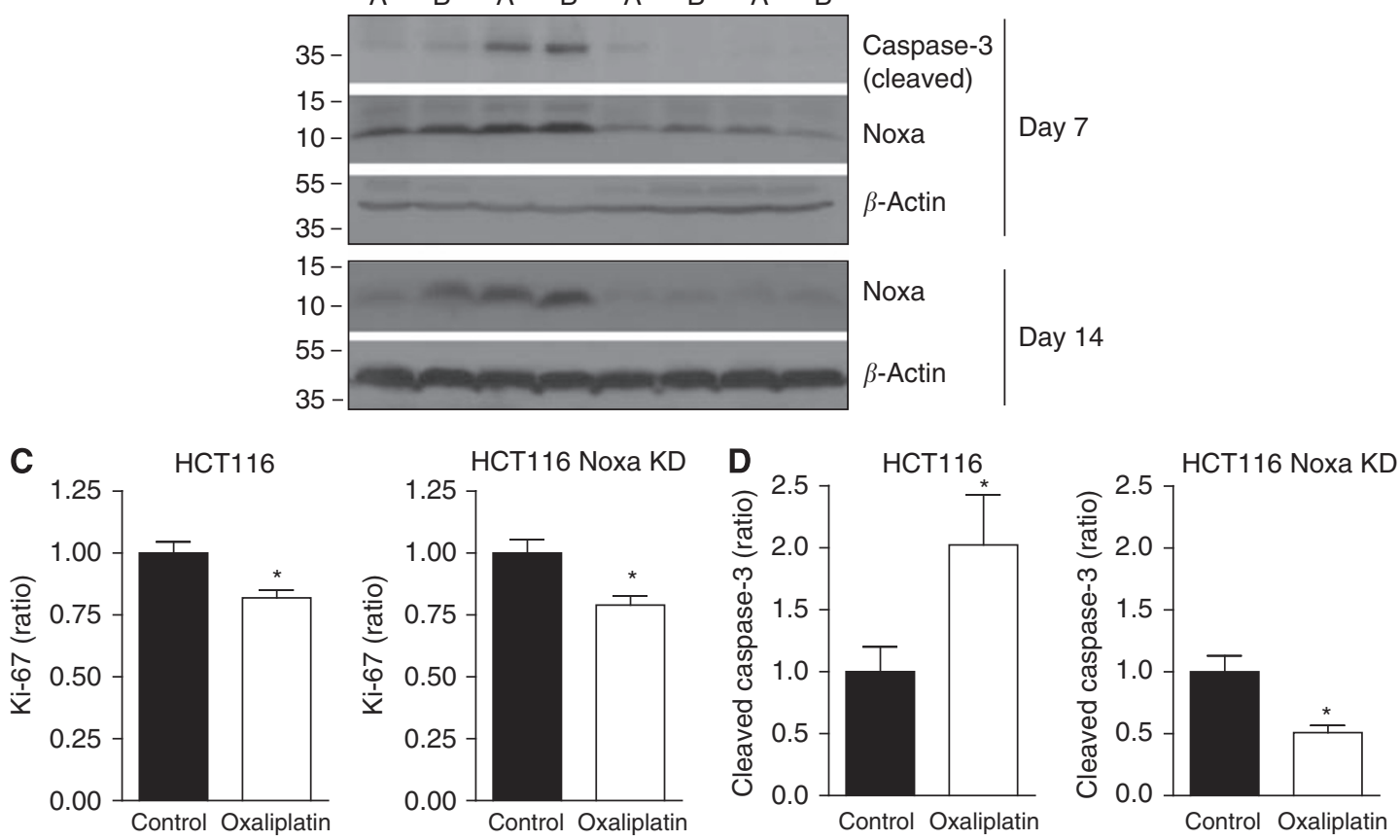

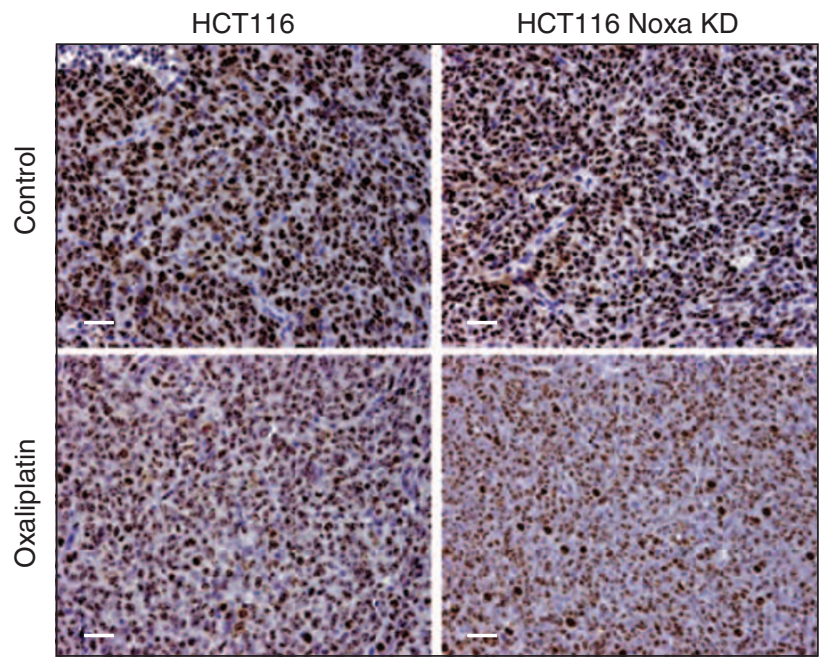

Ki-67

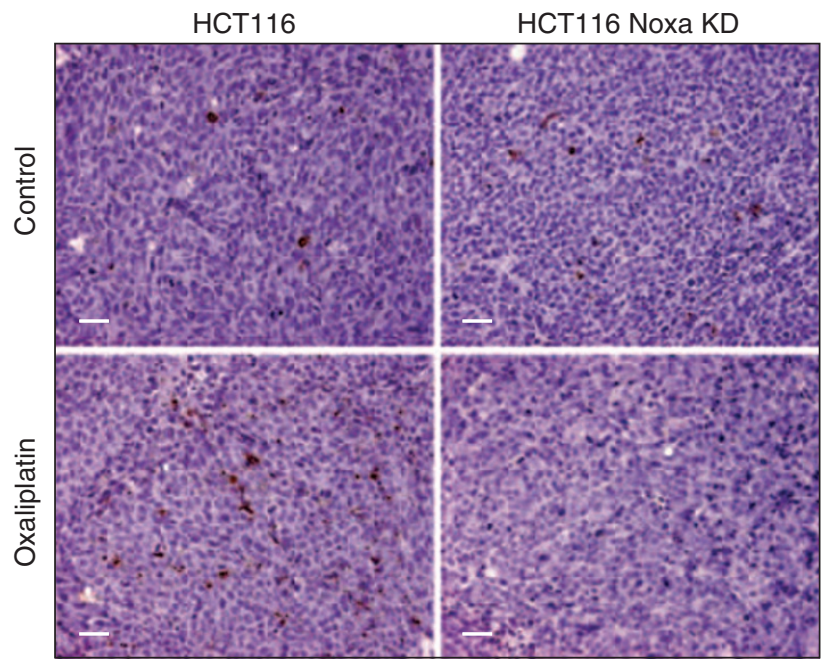

Cleaved caspase-3 
markers for proliferation and apoptosis, respectively. Noxa suppression was stable during the course of the experiment (Figure 6B). Induction of caspase- 3 processing by oxaliplatin was completely abolished in Noxa-suppressed tumours (Figure 6B and D). Oxaliplatin had a marginal but statistically significant inhibitory effect on tumour cell proliferation, but this was not affected by Noxa suppression (Figure 6C). These results show that Noxa is a key determinant of the apoptotic, but not the cytostatic response of HCT116 tumours to oxaliplatin chemotherapy.

\section{DISCUSSION}

In this study, we provide evidence that oncogenic KRAS facilitates chemotherapy-induced apoptosis of HCT116 colorectal tumour cells by cooperating with p53 in the induction of the pro-apoptotic gene Noxa. p53-dependent induction of PUMA did not require oncogenic KRAS. Both PUMA and Noxa belong to the class of $\mathrm{BH} 3$-only proteins that function as neutralisers of the pro-survival Bcl-2-like proteins (Willis and Adams, 2005). The contribution of PUMA and Noxa to apoptosis induction varies considerably between cell types (Shibue et al, 2003, 2006; Villunger et al, 2003; Michalak et al, 2008). Apoptosis induction in colorectal cancer cells by chemotherapy is partly $(\sim 50 \%)$ dependent on the induction of PUMA (Wang et al, 2007). Noxa is expressed both in the normal intestine and in most intestinal tumours (Jansson et al, 2003), and Noxa deficiency strongly reduces p53-dependent apoptosis in intestinal crypts following $\gamma$-irradiation (Shibue et al, 2003). Our results show that Noxa also has an essential role in chemotherapy-induced KRAS/p53-dependent apoptosis induction in intestinal (colorectal) cancer cells. Taken together, optimal p53-dependent apoptosis in colorectal cancer cells presumably requires induction of both Noxa and PUMA to achieve maximal neutralisation of Bcl-2 pro-survival proteins.

Importantly, p53 is not the only regulator of Noxa gene expression. Transcription factors such as c-Myc, E2F1, and HIF1 $\alpha$ regulate Noxa expression in a p53-independent manner (Hershko and Ginsberg, 2004; Hershko et al, 2005; Nikiforov et al, 2007; Ploner et al, 2008). Interestingly, oncogenic KRAS is critical for maintaining high c-Myc levels in the HCT116/Hkh2 system (Shirasawa et al, 1993), and can promote expression of E2F1 (Berkovich and Ginsberg, 2001) and stabilisation of HIF1 $\alpha$ (Kikuchi et al, 2009). The stimulatory effect of oncogenic KRAS on one or more of these transcription factors may explain why basal Noxa levels are low in KRAS ${ }^{D 13}$-deleted tumour cells. p53 is not required for maintaining basal levels of Noxa, but cooperates with oncogenic KRAS to induce Noxa expression in response to chemotherapy.

Expression of the H-Ras oncogene in primary cells causes stabilisation of $\mathrm{p} 53$ by induction of the tumour suppressor $\mathrm{p} 19^{\mathrm{ARF}}$ (p14 ${ }^{\mathrm{ARF}}$ in human cells) (Palmero et al, 1998). However, despite the presence of a mutant KRAS allele in HCT116 cells, its p14 ${ }^{\mathrm{ARF}}$ levels are relatively low (Javelaud and Besancon, 2002), and we did not observe overt differences in basal or chemotherapy-induced p53 stabilisation in cells with or without KRAS ${ }^{\text {D13 }}$. The control of p53 signalling output by oncogenic KRAS may therefore involve alterations in p53 post-translational modifications and/or binding partners. Our study showed that deletion of KRAS ${ }^{D 13}$ strongly reduced chemotherapy-induced phosphorylation of p53 at Ser37 and Ser392. Phosphorylation of both residues has been associated with the transcriptional output of p53, although not with apoptosis-specific gene regulation. As KRAS status did not affect p53 stabilisation or p21 induction, KRAS ${ }^{D 13}$-controlled phosphorylation of Ser37 and/or Ser392 may contribute to specifying p53 target gene induction. Interestingly, Ser37 phosphorylation augments p53 acetylation by p300 (Sakaguchi et al, 1998) and this promotes Noxa induction and apoptosis (Terui et al, 2003). Phosphorylation of p53 at Ser46, Ser15, and Ser20 has also been implicated in apoptosis-specific p53 signalling (Aylon and Oren, 2007). However, phosphorylation of these residues was either not detected (Ser20, Ser46) or not regulated by KRAS status (Ser15) in the HCT116 cell system.

Several additional determinants of the tumour cell response to p53 activation have been identified. These include p53 posttranslational modifications, interaction partners, and proteins that occupy p53 target gene promoters independently of p53 (Vousden and Prives, 2009). Whether oncogenic KRAS alters any of these additional pathways or whether differential phosphorylation at Ser37 and/or Ser392 is sufficient to skew p53 signalling output towards Noxa induction and apoptosis will be the subject of further studies.

Oxaliplatin and 5-FU are the mainstay chemotherapeutics in the treatment of patients with disseminated colorectal cancer. However, there are currently no reliable predictors for response to chemotherapy (Allen et al, 2006; Longley et al, 2006; Walther et al, 2009). Meta-analyses of the literature on the impact of p53 abnormalities and KRAS mutations on therapy outcome showed that neither p53 nor KRAS status had a predictive value (Munro et al, 2005; Loriot et al, 2009). Our results suggest that tumours expressing oncogenic KRAS in combination with wild-type p53 may respond best to chemotherapy. To the best of our knowledge, this has so far not been addressed in large patient cohorts. Noxa expression in a cohort of colorectal cancer patients treated with 5 -FU was unrelated to treatment response (Sinicrope et al, 2008). However, such negative correlations are hard to interpret, given that Noxa induction in response to chemotherapy is transient. Colorectal tumours express Noxa at normal levels (Jansson et al, 2003), and inactivating mutations have so far not been reported. Therefore, the loss of Noxa function does not seem to be required during colorectal tumour development. Indeed, the Noxa-dependent apoptosis pathway is intact in colorectal tumour cells (Ravi et al, 2004; Okumura et al, 2008). Furthermore, Noxa has been identified as a tumour-specific inducer of breast carcinoma cell death that spares non-transformed mammary cells (Suzuki et al, 2009). These observations suggest that the Noxa pathway may be an attractive target for therapeutic exploitation.

\section{ACKNOWLEDGEMENTS}

MTdB was supported by a grant from the AICR (07-552). DAER was supported by a grant from the Vanderes Foundation (07-177). FJHH was supported by a grant from the PON Foundation. WJvH was supported by a grant from the Dutch Organization for Medical Scientific Research (ZON-Mw; 920-03-313).

Supplementary Information accompanies the paper on British Journal of Cancer website (http://www.nature.com/bjc)

\section{REFERENCES}

Adamsen BL, Kravik KL, Clausen OP, De Angelis PM (2007) Apoptosis, cell cycle progression and gene expression in TP53-depleted HCT116 colon cancer cells in response to short-term 5 -fluorouracil treatment. Int $J$ Oncol 31: $1491-1500$
Allen WL, Coyle VM, Johnston PG (2006) Predicting the outcome of chemotherapy for colorectal cancer. Curr Opin Pharmacol 6: 332-336 Andreyev HJ, Norman AR, Cunningham D, Oates J, Dix BR, Iacopetta BJ, Young J, Walsh T, Ward R, Hawkins N, Beranek M, Jandik P, 
Benamouzig R, Jullian E, Laurent-Puig P, Olschwang S, Muller O, Hoffmann I, Rabes HM, Zietz C, Troungos C, Valavanis C, Yuen ST, Ho JW, Croke CT, O’Donoghue DP, Giaretti W, Rapallo A, Russo A, Bazan V, Tanaka M, Omura K, Azuma T, Ohkusa T, Fujimori T, Ono Y, Pauly M, Faber C, Glaesener R, de Goeij AF, Arends JW, Andersen SN, Lovig T, Breivik J, Gaudernack G, Clausen OP, De Angelis PD, Meling GI, Rognum TO, Smith R, Goh HS, Font A, Rosell R, Sun XF, Zhang H, Benhattar J, Losi L, Lee JQ, Wang ST, Clarke PA, Bell S, Quirke P, Bubb VJ, Piris J, Cruickshank NR, Morton D, Fox JC, Al-Mulla F, Lees N, Hall CN, Snary D, Wilkinson K, Dillon D, Costa J, Pricolo VE, Finkelstein SD, Thebo JS, Senagore AJ, Halter SA, Wadler S, Malik S, Krtolica K, Urosevic N (2001) Kirsten ras mutations in patients with colorectal cancer: the 'RASCAL II' study. Br J Cancer 85: 692-696

Andreyev HJ, Norman AR, Cunningham D, Oates JR, Clarke PA (1998) Kirsten ras mutations in patients with colorectal cancer: the multicenter 'RASCAL' study. J Natl Cancer Inst 90: 675-684

Aneja R, Ghaleb AM, Zhou J, Yang VW, Joshi HC (2007) p53 and p21 determine the sensitivity of noscapine-induced apoptosis in colon cancer cells. Cancer Res 67: $3862-3870$

Aylon Y, Oren M (2007) Living with p53, dying of p53. Cell 130: 597-600 Bardeesy N, Sharpless NE (2006) RAS unplugged: negative feedback and oncogene-induced senescence. Cancer Cell 10: 451-453

Berkovich E, Ginsberg D (2001) Ras induces elevation of E2F-1 mRNA levels. J Biol Chem 276: 42851-42856

Borralho PM, Moreira da Silva IB, Aranha MM, Albuquerque C, Nobre LC, Steer CJ, Rodrigues CM (2007) Inhibition of Fas expression by RNAi modulates 5-fluorouracil-induced apoptosis in HCT116 cells expressing wild-type p53. Biochim Biophys Acta 1772: 40-47

Braun CJ, Zhang X, Savelyeva I, Wolff S, Moll UM, Schepeler T, Orntoft TF, Andersen CL, Dobbelstein M (2008) p53-responsive microRNAs 192 and 215 are capable of inducing cell cycle arrest. Cancer Res 68: $10094-10104$

Chau I, Cunningham D (2009) Treatment in advanced colorectal cancer: what, when and how? Br J Cancer 100: 1704-1719

Ferbeyre G, de SE, Lin AW, Querido E, McCurrach ME, Hannon GJ, Lowe SW (2002) Oncogenic ras and p53 cooperate to induce cellular senescence. Mol Cell Biol 22: 3497-3508

Haigis KM, Kendall KR, Wang Y, Cheung A, Haigis MC, Glickman JN, Niwa-Kawakita M, Sweet-Cordero A, Sebolt-Leopold J, Shannon KM, Settleman J, Giovannini M, Jacks T (2008) Differential effects of oncogenic K-Ras and N-Ras on proliferation, differentiation and tumor progression in the colon. Nat Genet 40: 600-608

Hershko T, Chaussepied M, Oren M, Ginsberg D (2005) Novel link between E2F and p53: proapoptotic cofactors of p53 are transcriptionally upregulated by E2F. Cell Death Differ 12: 377-383

Hershko T, Ginsberg D (2004) Up-regulation of Bcl-2 homology 3 (BH3)-only proteins by E2F1 mediates apoptosis. J Biol Chem 279: $8627-8634$

Jansson AK, Emterling AM, Arbman G, Sun XF (2003) Noxa in colorectal cancer: a study on DNA, mRNA and protein expression. Oncogene 22: $4675-4678$

Javelaud D, Besancon F (2002) Inactivation of p21WAF1 sensitizes cells to apoptosis via an increase of both p14ARF and p53 levels and an alteration of the Bax/Bcl-2 ratio. J Biol Chem 277: 37949-37954

Khokhlatchev A, Rabizadeh S, Xavier R, Nedwidek M, Chen T, Zhang XF, Seed B, Avruch J (2002) Identification of a novel Ras-regulated proapoptotic pathway. Curr Biol 12: 253-265

Kikuchi H, Pino MS, Zeng M, Shirasawa S, Chung DC (2009) Oncogenic KRAS and BRAF differentially regulate hypoxiainducible factor-1alpha and -2alpha in colon cancer. Cancer Res 69: $8499-8506$

Klampfer L, Swaby LA, Huang J, Sasazuki T, Shirasawa S, Augenlicht L (2005) Oncogenic Ras increases sensitivity of colon cancer cells to 5-FUinduced apoptosis. Oncogene 24: $3932-3941$

Kuribayashi K, El-Deiry WS (2008) Regulation of programmed cell death by the p53 pathway. Adv Exp Med Biol 615: 201-221

Lin AW, Lowe SW (2001) Oncogenic ras activates the ARF-p53 pathway to suppress epithelial cell transformation. Proc Natl Acad Sci USA 98: $5025-5030$

Lindqvist A, van ZW, Karlsson RC, Wolthuis RM (2007) Cyclin B1-Cdk1 activation continues after centrosome separation to control mitotic progression. PLoS Biol 5: e123

Longley DB, Allen WL, Johnston PG (2006) Drug resistance, predictive markers and pharmacogenomics in colorectal cancer. Biochim Biophys Acta 1766: 184-196
Loriot Y, Mordant P, Deutsch E, Olaussen KA, Soria JC (2009) Are RAS mutations predictive markers of resistance to standard chemotherapy? Nat Rev Clin Oncol 6: 528-534

Michalak EM, Villunger A, Adams JM, Strasser A (2008) In several cell types tumour suppressor p53 induces apoptosis largely via Puma but Noxa can contribute. Cell Death Differ 15: 1019-1029

Munro AJ, Lain S, Lane DP (2005) P53 abnormalities and outcomes in colorectal cancer: a systematic review. $\mathrm{Br} J$ Cancer 92: $434-444$

Nikiforov MA, Riblett M, Tang WH, Gratchouck V, Zhuang D, Fernandez Y, Verhaegen $M$, Varambally $S$, Chinnaiyan AM, Jakubowiak AJ, Soengas MS (2007) Tumor cell-selective regulation of NOXA by c-MYC in response to proteasome inhibition. Proc Natl Acad Sci USA 104: $19488-19493$

Oda E, Ohki R, Murasawa H, Nemoto J, Shibue T, Yamashita T, Tokino T, Taniguchi T, Tanaka N (2000) Noxa, a BH3-only member of the Bcl-2 family and candidate mediator of p53-induced apoptosis. Science 288: $1053-1058$

Okumura K, Huang S, Sinicrope FA (2008) Induction of Noxa sensitizes human colorectal cancer cells expressing Mcl-1 to the small-molecule Bcl-2/Bcl-xL inhibitor, ABT-737. Clin Cancer Res 14: $8132-8142$

Oren M (2003) Decision making by p53: life, death and cancer. Cell Death Differ 10: $431-442$

Palmero I, Pantoja C, Serrano M (1998) p19ARF links the tumour suppressor p53 to Ras. Nature 395: $125-126$

Ploner C, Kofler R, Villunger A (2008) Noxa: at the tip of the balance between life and death. Oncogene 27 (Suppl 1): S84-S92

Ravi R, Jain AJ, Schulick RD, Pham V, Prouser TS, Allen H, Mayer EG, Yu H, Pardoll DM, Ashkenazi A, Bedi A (2004) Elimination of hepatic metastases of colon cancer cells via p53-independent cross-talk between irinotecan and Apo2 ligand/TRAIL. Cancer Res 64: 9105-9114

Ries S, Biederer C, Woods D, Shifman O, Shirasawa S, Sasazuki T, McMahon M, Oren M, McCormick F (2000) Opposing effects of Ras on p53: transcriptional activation of $\mathrm{mdm} 2$ and induction of p19ARF. Cell 103: $321-330$

Ruiz L, Traskine M, Ferrer I, Castro E, Leal JF, Kaufman M, Carnero A (2008) Characterization of the p53 response to oncogene-induced senescence. PLoS One 3: e3230

Sakaguchi K, Herrera JE, Saito S, Miki T, Bustin M, Vassilev A, Anderson CW, Appella E (1998) DNA damage activates p53 through a phosphorylation-acetylation cascade. Genes Dev 12: 2831-2841

Serrano M, Lin AW, McCurrach ME, Beach D, Lowe SW (1997) Oncogenic ras provokes premature cell senescence associated with accumulation of p53 and p16INK4a. Cell 88: 593-602

Shibue T, Suzuki S, Okamoto H, Yoshida H, Ohba Y, Takaoka A, Taniguchi T (2006) Differential contribution of Puma and Noxa in dual regulation of p53-mediated apoptotic pathways. EMBO J 25: $4952-4962$

Shibue T, Takeda K, Oda E, Tanaka H, Murasawa H, Takaoka A, Morishita Y, Akira S, Taniguchi T, Tanaka N (2003) Integral role of Noxa in p53-mediated apoptotic response. Genes Dev 17: 2233-2238

Shibue T, Taniguchi T (2006) BH3-only proteins: integrated control point of apoptosis. Int J Cancer 119: 2036-2043

Shirasawa S, Furuse M, Yokoyama N, Sasazuki T (1993) Altered growth of human colon cancer cell lines disrupted at activated Ki-ras. Science 260: $85-88$

Sinicrope FA, Rego RL, Okumura K, Foster NR, O'Connell MJ, Sargent DJ, Windschitl HE (2008) Prognostic impact of bim, puma, and noxa expression in human colon carcinomas. Clin Cancer Res 14: $5810-5818$

Smakman N, van den Wollenberg DJ, Elias SG, Sasazuki T, Shirasawa S, Hoeben RC, Borel RI, Kranenburg O (2006) KRAS(D13) promotes apoptosis of human colorectal tumor cells by ReovirusT3D and oxaliplatin but not by tumor necrosis factor-related apoptosis-inducing ligand. Cancer Res 66: 5403-5408

Suzuki S, Nakasato M, Shibue T, Koshima I, Taniguchi T (2009) Therapeutic potential of proapoptotic molecule Noxa in the selective elimination of tumor cells. Cancer Sci 100: 759-769

Terui T, Murakami K, Takimoto R, Takahashi M, Takada K, Murakami T, Minami S, Matsunaga T, Takayama T, Kato J, Niitsu Y (2003) Induction of PIG3 and NOXA through acetylation of p53 at 320 and 373 lysine residues as a mechanism for apoptotic cell death by histone deacetylase inhibitors. Cancer Res 63: 8948-8954 
Toscano F, Parmentier B, Fajoui ZE, Estornes Y, Chayvialle JA, Saurin JC Abello J (2007) p53 dependent and independent sensitivity to oxaliplatin of colon cancer cells. Biochem Pharmacol 74: 392-406

Villunger A, Michalak EM, Coultas L, Mullauer F, Bock G, Ausserlechner MJ, Adams JM, Strasser A (2003) p53- and drug-induced apoptotic responses mediated by $\mathrm{BH} 3$-only proteins puma and noxa. Science 302: $1036-1038$

Vos MD, Ellis CA, Bell A, Birrer MJ, Clark GJ (2000) Ras uses the novel tumor suppressor RASSF1 as an effector to mediate apoptosis. J Biol Chem 275: 35669-35672

Vousden KH, Lu X (2002) Live or let die: the cell's response to p53. Nat Rev Cancer 2: $594-604$
Vousden KH, Prives C (2009) Blinded by the light: the growing complexity of p53. Cell 137: 413-431

Walther A, Johnstone E, Swanton C, Midgley R, Tomlinson I, Kerr D (2009) Genetic prognostic and predictive markers in colorectal cancer. Nat Rev Cancer 9: 489-499

Wang P, Yu J, Zhang L (2007) The nuclear function of p53 is required for PUMA-mediated apoptosis induced by DNA damage. Proc Natl Acad Sci USA 104: 4054-4059

Willis SN, Adams JM (2005) Life in the balance: how BH3-only proteins induce apoptosis. Curr Opin Cell Biol 17: 617-625

Yu J, Zhang L (2005) The transcriptional targets of p53 in apoptosis control. Biochem Biophys Res Commun 331: 851-858 